\title{
The impact of flavonoids-rich Ziziphus jujuba Mill. Extract on Staphylococcus aureus biofilm formation
}

Weiwei Miao ${ }^{1,2+}$, Lei Sheng ${ }^{3 \dagger}$, Tao Yang ${ }^{3}$, Guizhen Wu $^{3}$, Minfang Zhang ${ }^{3}$, Juan Sun ${ }^{4^{*}}$ and Aikemu Ainiwaer ${ }^{1^{*}}$

\begin{abstract}
Background: To evaluate the in vitro antibacterial effect of flavonoids-rich Ziziphus jujuba Mill. extract (FZM) against the formation of bacterial biofilms (BBFs) in Staphylococcus aureus.

Results: FZM can effectively inhibit the formation of S. aureus biofilms in vitro. Morphological observation showed a decrease in both biofilm adhesion and thickness. Results of confocal laser scanning microscopy used to detect the thickness of the BBFs showed that FZM treatment reduced the thickness of the BBFs. Furthermore, after the Image-Pro Plus v.6.0 analysis of the fluorescence intensity, FZM treatment reduced the thickness of the BBFs as well as the proportion of green fluorescence. Scanning electron microscopy showed that FZM can disrupt the channels available for substance exchange in the biofilm, thus exposing the bacterial cells and damaging its three-dimensional structures. Conclusion: FZM can inhibit biofilm formation, improve the bacterial pH environment, and eliminate the hydrophobic effect of reactive oxygen species and flavonoids.
\end{abstract}

Keywords: Flavonoids-rich Ziziphus jujuba mill. Extract, Staphylococcus aureus, Bacterial biofilm, Crystal violet assays, Confocal laser scanning microscope, Scanning electron microscope

\section{Background}

Jujube (Ziziphus jujuba Mill.) fruit, commonly called as the sour or round date, has been used for medical purposes for more than 2000 years. It is an important raw material in food and pharmaceutical industries. Approximately $90 \%$ of the world's $Z$. jujuba is produced in China, where it is widely distributed from Urumqi, Xinjiang. Owing to the extremely strong sedative and tranquilizing effect of this fruit, traditional Chinese medicine often uses the dried seeds for medicinal purposes. The jujube fruit is often wasted, but there are a few studies reporting its medicinal value. The present study analyzed the antibacterial effects of $Z$. jujuba flavonoid on bacterial biofilms $[1,2]$. Flavonoids are the major chemical components of jujube [2]. Flavonoids

\footnotetext{
* Correspondence: 454726435@qq.com; ainiwa@sina.com

${ }^{+}$Weiwei Miao and Lei Sheng contributed equally to this work.

${ }^{4}$ Heart Center, The First Affiliated Hospital of Xinjiang Medical University, Urumai 830011, China

${ }^{1}$ Clinical Medical Research Institute, The First Affiliated Hospital of Xinjiang

Medical University, Urumqi 830011, China

Full list of author information is available at the end of the article
}

isolated from jujube are reported to exhibit a strong antibacterial effect [3]. Although free individual bacteria are easily cleared by antibiotics, once bacteria form advanced structures, such as bacterial biofilms (BBFs), they are less susceptible to antibiotics, leading to antibiotic resistance $[4,5]$.

In the present study, we used crystal violet assays, optical microscopy, confocal laser scanning microscopy, and scanning electron microscopy to determine the antimicrobial activity of FZM against Staphylococcus aureus biofilm formation.

\section{Methods \\ Materials}

Ziziphus jujuba Mill. (Purchased from Xinjiang Maidisen Pharmaceutical Company (No.M30062307). The quality inspection report provided by Xinjiang Maidisen Pharmaceutical Company was identified as the dry and mature fruit of Ziziphus jujuba Mill. var.spinosa (Bunge) Hu ex. H.F. Chow by Miregiuli, the quality inspector of Madison), ethanol anhydrous (Tianjin Yongsheng Chemical Co., Ltd. No.20160303), brain heart infusion broth 
Table 1 Effect of FZM on biofilm formation evaluated by crystal violet assays

\begin{tabular}{|c|c|c|c|c|c|c|c|c|}
\hline \multirow[t]{2}{*}{ Group } & \multicolumn{7}{|c|}{$\mathrm{FZM} / \mu \mathrm{g} \cdot \mathrm{mL}^{-1}$} & \multirow[t]{2}{*}{ Ampicillin } \\
\hline & 0 & 1.41 & 2.81 & 5.63 & 11.3 & 22.5 & 45 & \\
\hline $\mathrm{OD}_{600}$ & $0.565 \pm 0.01$ & $0.313 \pm 0.02^{*}$ & $0.217 \pm 0.02^{*}$ & $0.177 \pm 0.01^{*}$ & $0.074 \pm 0.01^{*}$ & $0.082 \pm 0.01^{*}$ & $0.085 \pm 0.01^{*}$ & $0.113 \pm 0.01^{*}$ \\
\hline Inhibitory rate\% & $10.8 \%$ & $50.6 \%$ & $65.7 \%$ & $75.9 \%$ & $88.3 \%$ & $87.0 \%$ & $86.6 \%$ & $82.2 \%$ \\
\hline
\end{tabular}

Compare to the control group ${ }^{*} P<0.05$

(BHI; Qingdao Riyong Biological Technology Co., Ltd. No.20160511), crystal violet (Shanghai Hansi Chemical Co., Ltd. No.GC60036), ampicillin (Solarbio No.A8180), normal saline (Sichuan Kelun Pharmaceutical Co., Ltd. No.L116031201), sodium deoxycholate (Sigma-Aldrich, No.30970), 2.5\% glutaraldehyde solution (Shanghai Gefan Biological Technology Co., Ltd. No.M011), phosphate buffered solution (PBS; Hyclone, No.SH30256.01), FITC-Concanavalin A (Sigma No.C7642), propidium iodide (PI; Solarbio No.P8080), blood agar base medium (Solarbio, No.RPY-569), cover glass $(18 \times 18 \mathrm{~mm}$ CITO GLAS No.10211818C), slide glass $(25 \times 75 \mathrm{~mm}$ CITO GLAS No.188105), Petri dish $(15 \times 60 \mathrm{~mm}$, NEST No.705001), 96-well plates (NEST No.20160120801A), $\mathrm{CO}_{2}$ incubator (Hera Cell-150 Thermo, Waltham USA), biosafety cabinet (KS-18 Thermo, Waltham USA), microplate reader (Model 680 Bio-Rad, Thermo, Waltham USA), confocal laser scanning microscope (C2 Nikon, Tokyo Japan), electron microscope (CTR6000 Leica, Wetzlar Germany), scanning electron microscope (JSM-6390, Tokyo Japan), $S$. aureus (provided by the Basic Medical College of Xinjiang Medical University, ATCC25923).

\section{Preparation of $Z$. jujube extract}

In this study, dried ripe Z. jujube fruit was used. Quality control was conducted by Quality Inspector Mireguli from Xinjiang Madison Pharmaceutical Co., Ltd. Jujubes were picked, cleaned, cored, sliced, dried, and ground into 100-mesh powder. The powder was mixed with ethanol $\left(1: 15, \mathrm{~g} \cdot \mathrm{mL}^{-1}\right)$ and extracted by reflux for $1.5 \mathrm{~h}$ at $70{ }^{\circ} \mathrm{C}$. The supernatant was collected by centrifugation, further concentrated, and dried as jujube extract for further use.

\section{Impact of FZM on BBF formation Crystal violet assays}

An isolated colony of standard $S$. aureus was streaked with an inoculation needle and incubated for $24 \mathrm{~h}$ at $37^{\circ} \mathrm{C}$. Subsequently, an isolated colony was diluted in $\mathrm{BHI}$ medium and cultivated at $37^{\circ} \mathrm{C}$ for $24 \mathrm{~h}$. After vortexing, the bacterial concentration was adjusted to $1 \times$ $10^{9} \mathrm{CFU} / \mathrm{mL}$ using McFarland standards.

Biofilms were created by adding $50 \mu \mathrm{L}$ of the bacterial suspension and $150 \mu \mathrm{L}$ of the BHI medium containing $1 \%$ sucrose to each well of a 96-well plate. They were grown at $37{ }^{\circ} \mathrm{C}$ in $5 \% \mathrm{CO}_{2}$ for $24 \mathrm{~h} \mathrm{[6].} \mathrm{The} \mathrm{supernatants}$ were removed, and the planktonic bacteria were washed away with PBS.

FZM was added to the test group at concentrations of $1.41,2.81,5.63,11.3,22.5$, and $45 \mu \mathrm{g} / \mathrm{mL}$. Ethanol was used as the negative control, and $0.25 \mathrm{mg} / \mathrm{mL}$ ampicillin was used as the positive control [7]. There were four replicates of each. The plates were incubated at $37^{\circ} \mathrm{C}$ in $5 \% \mathrm{CO}_{2}$ for $24 \mathrm{~h}$. The supernatants were removed, and

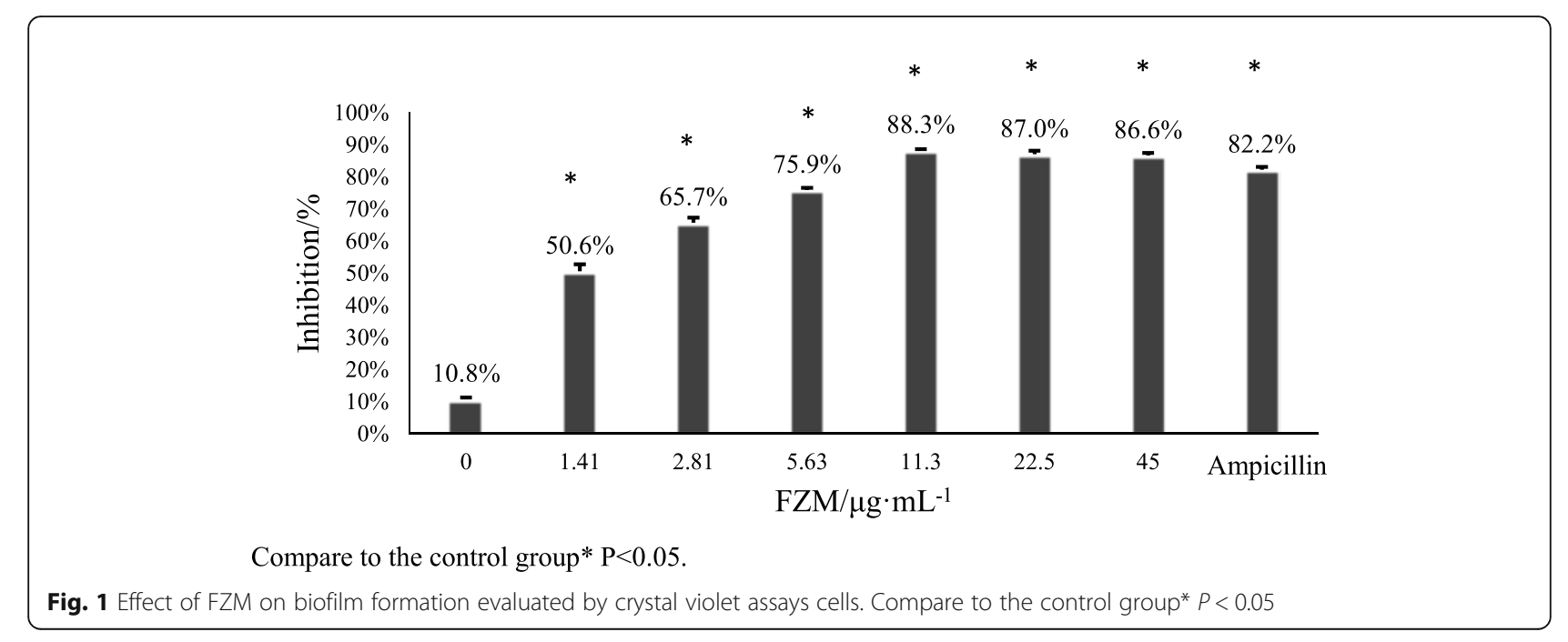




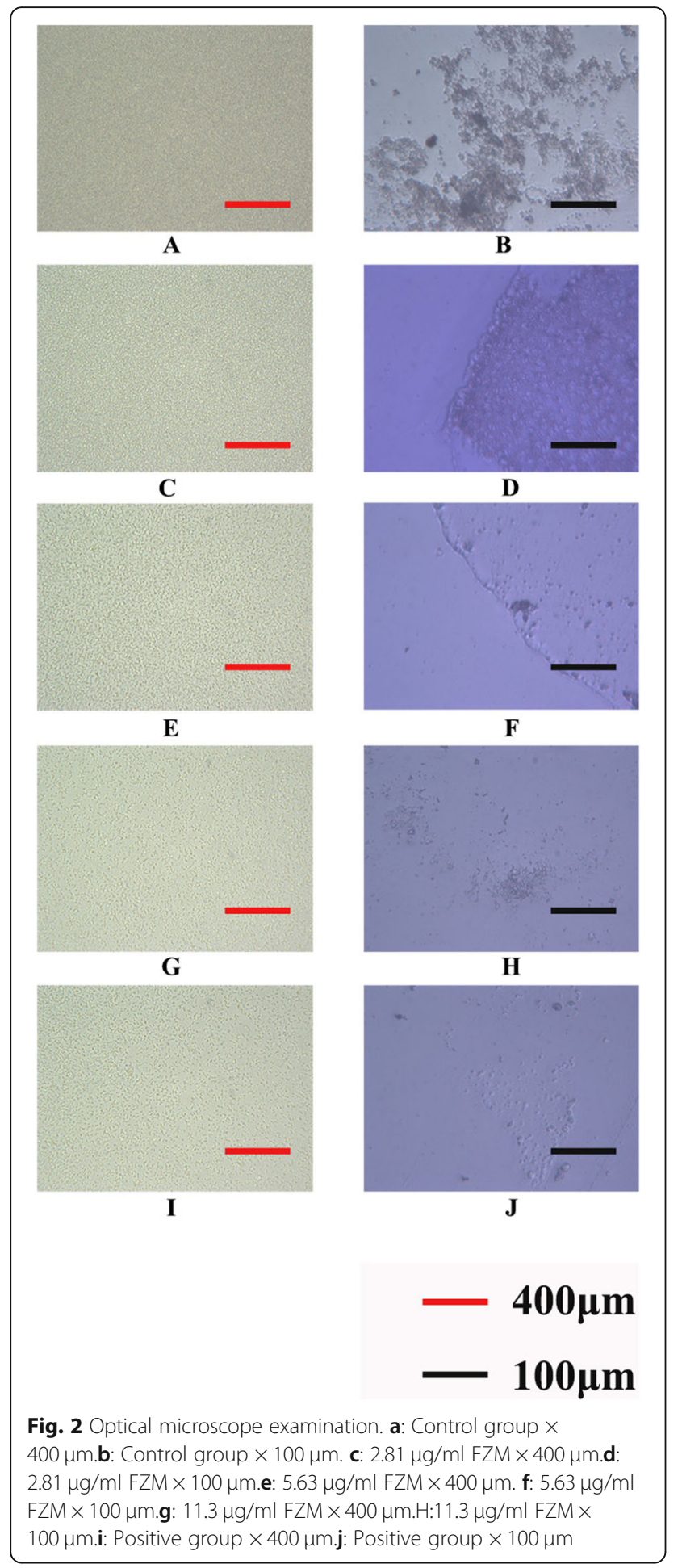

the plates were washed three times with PBS. Plates were dried at room temperature for $30 \mathrm{~min}$, after which $200 \mu \mathrm{L}$ of $0.1 \%$ crystal violet (CV) stain was added to each well and left for $15 \mathrm{~min}$, and wells were rinsed with distilled water until transparent. Next, $2 \%$ sodium deoxycholate was added to each well to detach the biofilms, and the $\mathrm{OD}_{600 \mathrm{~nm}}$ values were measured.

Bacteriostatic rate $(\%)=\left(\mathrm{OD}_{\text {blank control }}-\mathrm{OD}_{\text {test group }}\right) / \mathrm{OD}_{\text {blank control }} \times 100 \%$

\section{Optical microscopy}

Plates were prepared as described above. After $24 \mathrm{~h}$ of growth, the 96-well plates were stained with CV and fixed with $2.5 \%$ glutaraldehyde. The morphological changes were observed under an optical microscope.

\section{Confocal laser scanning microscopy}

Sterilized coverslips treated with concentrated sulfuric acid and $75 \%$ ethanol were placed in $15 \times 60-\mathrm{mm}$ Petri dishes. To each dish, $0.2 \mathrm{~mL}$ of the bacterial suspension and $4.8 \mathrm{~mL}$ of $\mathrm{BHI}$ medium were added. The dishes were incubated for $24 \mathrm{~h}$ at $37^{\circ} \mathrm{C}$ in $5 \% \mathrm{CO}_{2}$, and then, the media was discarded. FZM and control treatments were identical to the ones used above. After incubation for 24 $\mathrm{h}$, the coverslips were rinsed with PBS and fixed with $2.5 \%$ glutaraldehyde for $30 \mathrm{~min}$. Subsequently, they were rinsed with PBS, stained with FITC-ConA for $30 \mathrm{~min}$, stained with PI for $15 \mathrm{~min}$, and sealed [8]. Finally, they were observed under a confocal microscope with a sublaser. The centers of the specimen were used to determine the presence of biofilms. The thickest biofilm was imaged, and the thickness was recorded. Bacterial viability was determined using Image-Pro Plus v.6.0 to analyze the intensity of FITC-ConA fluorescence under confocal laser scanning microscopy (CLSM).

\section{Scanning electron microscopy}

To $15 \times 60$-mm Petri dishes, $0.2 \mathrm{~mL}$ bacterial suspension and $4.8 \mathrm{~mL}$ media were added, bacteria were cultured for $24 \mathrm{~h}$ at $37^{\circ} \mathrm{C}$ in $5 \% \mathrm{CO}_{2}$, and the media were then discarded. FZM and control treatments were identical to the ones used above. After rinsing with PBS, the dishes were fixed with $2 \%$ glutaric acid, dehydrated with anhydrous ethanol, dried with $\mathrm{CO}_{2}$, and sputter-coated with

Table 2 BBFs thickness and the vital bacterial percentage

\begin{tabular}{|c|c|c|c|c|c|c|c|c|}
\hline \multirow[t]{2}{*}{ Group } & \multicolumn{7}{|c|}{$\mathrm{FZM} / \mu \mathrm{g} \cdot \mathrm{mL}^{-1}$} & \multirow[t]{2}{*}{ Ampicillin } \\
\hline & 0 & 1.41 & 2.81 & 5.63 & 11.3 & 22.5 & 45 & \\
\hline Bacterial biofilm thickness/ $\mu \mathrm{m}$ & $82.3 \pm 0.63^{*}$ & $65.6 \pm 1.05^{*}$ & $36.0 \pm 0.94^{*}$ & $13.0 \pm 0.49^{*}$ & $7.30 \pm 0.75^{*}$ & $6.60 \pm 0.10^{*}$ & $6.30 \pm 0.48^{*}$ & $2.10 \pm 0.48$ \\
\hline Fluorescence intensity/(a.u.) & $90.5 \pm 3.30^{*}$ & $81.2 \pm 0.52^{*}$ & $47.8 \pm 0.12^{*}$ & $10.3 \pm 0.50^{*}$ & $10.1 \pm 0.03^{*}$ & $10.2 \pm 0.11^{*}$ & $10.0 \pm 0.59^{*}$ & $16.6 \pm 0.43$ \\
\hline
\end{tabular}




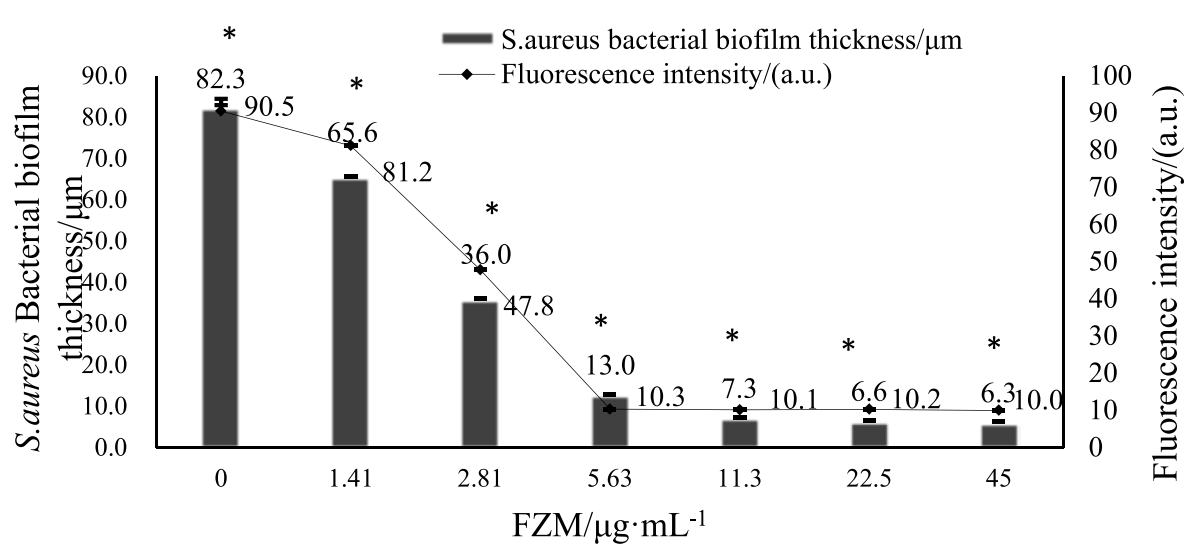

Compare to the control group ${ }^{*} P<0.05$.

Fig. 3 Effect of FZM on biofilm formation evaluated by crystal violet assays cells. Compare to the control group* $P<0.05$

gold. They were scanned using scanning electron microscopy (SEM) to determine the presence and morphology of BBFs.

\section{Statistical analysis}

SPSS 20.0 software was used for statistical analysis. If the data were normal, multiple groups were tested by one-way analysis of variance. If the variance was equal, Dunnett's $t$-test was used for evaluating the difference between each group and the control group. The Dunnett T3 test was used for the variance invariance, where $\alpha=0.05$. Data were represented as mean \pm standard deviation.

\section{Results}

Preparation of $Z$. jujube extract

The flavonoid concentration in the jujube extract was $1.44 \mathrm{mg} / \mathrm{g}$ at $510 \mathrm{~nm}$.

\section{Impact of FZM on BBF formation \\ Crystal violet assays}

The presence of FZM decreased the rate of biofilm formation. BBF formation decreased with increased FZM concentration and when the concentration of FZM at $11.3 \mu \mathrm{g} / \mathrm{mL}$, the inhibitory rate was maximal at $88.3 \%$. After $11.3 \mu \mathrm{g} / \mathrm{mL}$ of FZM, the inhibitory rate tended to be stable. Compared with the control group, these results were significantly different $(p<0.05)$. (Table 1, Fig. 1).

\section{Optical microscopy}

In the control group, S. aureus accumulated and aggregated into clusters with a high bacterial density. The bacteria formed complete biofilms. At $2.81 \mu \mathrm{g} / \mathrm{mL}$ of FZM, The biofilm began to fall off, but there was still mass adhesion, indicating that some of the BBFs had been destroyed. At $5.63 \mu \mathrm{g} / \mathrm{mL}$ of FZM, adhesion was further reduced, and the films were transparent, suggesting that FZM had a significant inhibitory effect on the bacteria at this concentration. At $11.3 \mu \mathrm{g} / \mathrm{mL}$ of FZM, most of the BBFs were detached, and the adhesion area and thickness were smaller than those of the BBFs in the positive control group, indicating that nearly all the biofilms had been removed. In the positive control group, BBF formation was significantly reduced with little adhesion remaining (Fig. 2).

\section{CLSM}

\section{BBF thickness and bacterial viability}

All concentrations impacted $S$. aureus BBF formation. BBFs thickness decreased with increasing FZM concentration. After $11.3 \mu \mathrm{g} . \mathrm{mL}^{-1}$ of FZM, the thickness of S.aureus biofilm tends to stabilize The thinnest BBFs were observed at $45 \mu \mathrm{g} / \mathrm{mL}$ of FZM $(6.30 \pm 0.48 \mu \mathrm{m})$. After $S$. aureus BFFs were treated with FZM, the number of viable bacteria significantly decreased. At $11.3 \mu \mathrm{g} / \mathrm{mL}$ of FZM, the intensity of fluorescence significantly decreased. The intensity of bacterial fluorescence was $11.3 \mu \mathrm{g} / \mathrm{mL}$ of FZM (10.1 \pm 0.03 a.u.). After $5.625 \mu \mathrm{g} \cdot \mathrm{mL}^{-1}$ of FZM, the level of fluorescence was stable. The results were significantly different from those of the control group $(p<0.05)$ (Table 2, Fig. 3).

\section{CLSM}

In the control group, S. aureus aggregated in clusters and the overlapping parts of the live and dead bacterial cells appeared yellow (green + red) [9]. The bacteria were embedded in a matrix formed by a number of polysaccharides (green), which exhibited a compact structure with complete biofilm formation. There was less green fluorescence in the cells treated with $1.41 \mu \mathrm{g} / \mathrm{mL}$ of FZM, indicating a reduced BBF polysaccharide matrix. The bacterial distribution was sparse, so BBFs were destroyed from this concentration onwards. At $2.81 \mu \mathrm{g} /$ $\mathrm{mL}$ of FZM, the bacterial density was significantly 


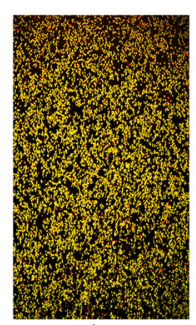

A
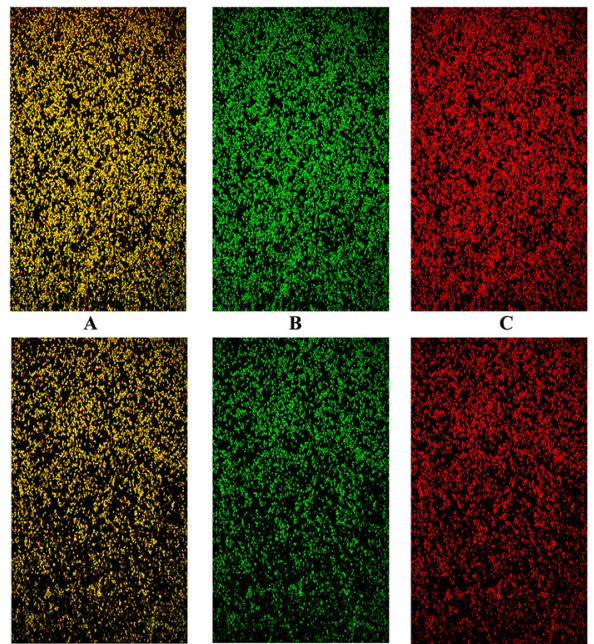

D
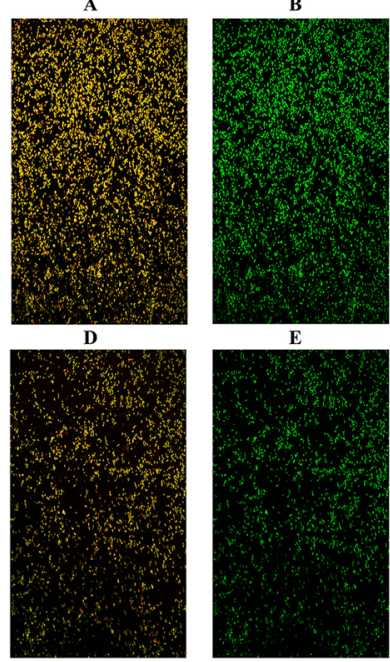

G

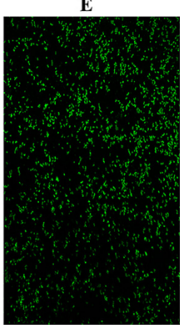

$\mathbf{H}$
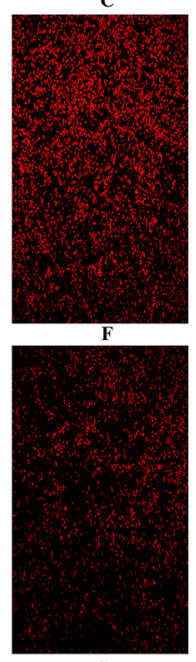

I $\overline{4 m m}$
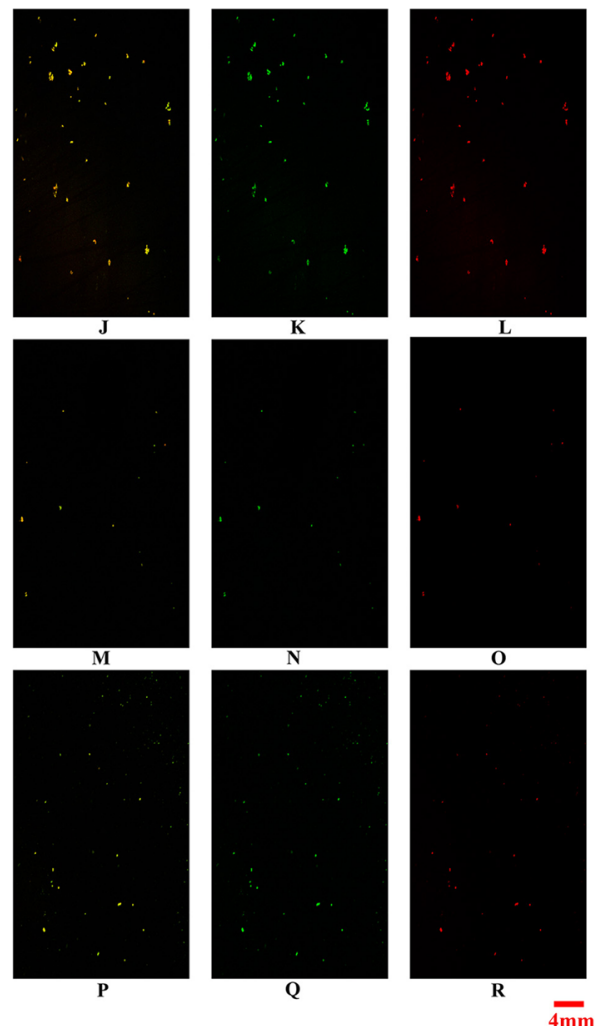

Fig. 4 Effect of FZM on biofilm formation evaluated by crystal violet assays cells. a:Control group $\times 4 \mathrm{~mm}$ Channels merged. $\mathbf{b}$ :Control group $\times 4 \mathrm{~mm}$ Green channel. c:Control group $\times 4 \mathrm{~mm}$ Red channel. d: $1.41 \mu \mathrm{g} / \mathrm{ml} \times 4 \mathrm{~mm}$ Channels merged. e1.41 $\mu \mathrm{g} / \mathrm{ml} \times 4 \mathrm{~mm}$ Green channel. f: $1.41 \mu \mathrm{g} / \mathrm{ml} \times 4 \mathrm{~mm}$ Red channel. g:2.81 $\mu \mathrm{g} / \mathrm{ml} \times 4 \mathrm{~mm}$ Channels merged. $\mathbf{h}: 2.81 \mu \mathrm{g} / \mathrm{ml} \times 4 \mathrm{~mm}$ Green channel. i:2.81 $\mathrm{gg} /$ $\mathrm{ml} \times 4 \mathrm{~mm}$ Red channel. j:5.63 $\mu \mathrm{g} / \mathrm{ml} \times 4 \mathrm{~mm}$ Channels merged. k:5.63 $\mu \mathrm{g} / \mathrm{ml} \times 4 \mathrm{~mm}$ Green channel. I:5.63 $\mu \mathrm{g} / \mathrm{ml} \times 4 \mathrm{~mm}$ Red channel. $\mathbf{m}: 11.3 \mu \mathrm{g} / \mathrm{ml} \times 4 \mathrm{~mm}$ Channels merged. $\mathbf{n}: 11.3 \mu \mathrm{g} / \mathrm{ml} \times 4$ $\mathrm{mm}$ Green channel. o: $11.3 \mu \mathrm{g} / \mathrm{ml} \times 4 \mathrm{~mm}$ Red channel. p:Positive group $\times 4 \mathrm{~mm}$ Channels merged. $\mathbf{q}$ :Positive group $\times 4 \mathrm{~mm}$ Green channel. r:Positive group $\times 4 \mathrm{~mm}$ Red channel

reduced, although clearly observable bacterial aggregations remained. This suggests that there is enhanced inhibition of FZM at this concentration with some remaining bacterial adhesions. At $5.63 \mu \mathrm{g} / \mathrm{mL}$ of FZM, the fluorescence was weak, most biofilms had disappeared, and the surrounding scattered star-shaped green fluorescence suggested the presence of a few planktonic bacteria. At $11.3 \mu \mathrm{g} / \mathrm{mL}$ of FZM, the fluorescent spots were barely visible, indicating that the biofilms had disappeared at this concentration. In the positive control group, there were a few clusters of low-density bacteria with large shedding of BBFs and only a small number of green and yellow dots. It shows that BBFs has been removed the BBFs had been removed. (Fig. 4-1, Fig. 4-2).

\section{SEM}

Different from biofilms formed by other bacteria, S.aureus formed biofilms were more dense, and $S$. aureus revealed grape-like clusters in biofilms $[10,11]$. Bacterial mucus filaments were easily identified in the negative control group. These filaments were tightly wrapped in mucus-like substances forming a large and dense membrane-like structure with an uneven appearance. The structure contained channels for water and nutrient exchange, which provided the necessary environment for a low level of bacterial growth and metabolism in the BBF dormant state [12]. The Staphylococcus aureus is tightly wrapped on the surface of Petri dish by bacterial biofilm. At $2.81 \mu \mathrm{g} / \mathrm{mL}$ of FZM, large accumulations of S. aureus cells and extracellular mucilage were clearly observed, indicating that there was still biofilm adhesion despite the inhibitory effect of FZM. At $5.63 \mu \mathrm{g} / \mathrm{mL}$ of FZM, visible microvilli were observed around the BBFs, and BBFs transmittance was stronger than that in the negative control group, indicating that FZM had some effects on BBFs at this concentration. At $11.3 \mu \mathrm{g} / \mathrm{mL}$ of FZM, most of the cells shrank and contained broken three-dimensional (3D) structures. Few cells were intact, but these were not coated with mucous and were clear, indicating that this concentration had a strong scavenging effect and that the bacterial structure began to disassemble. The density of $S$. aureus was significantly 


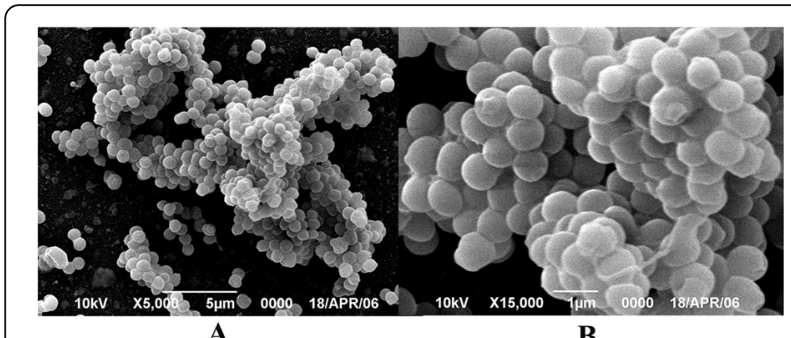

A B

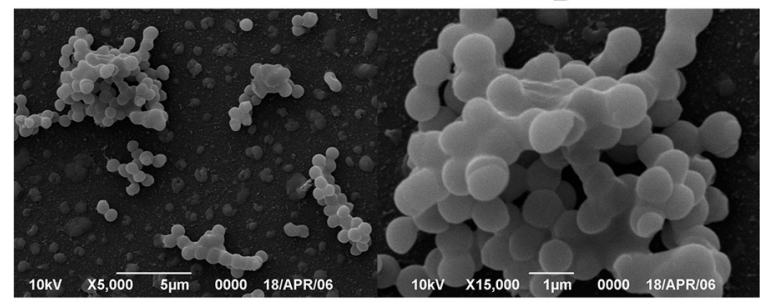

D

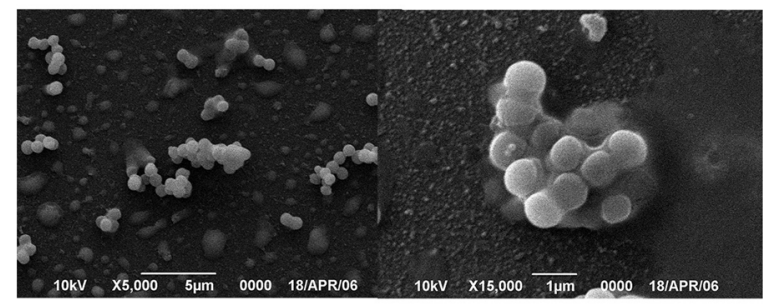

E F
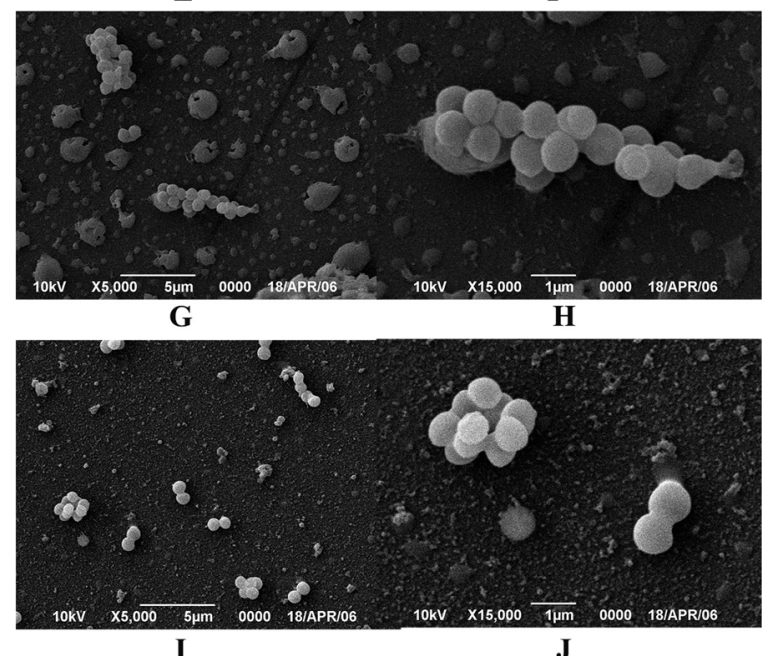

I

Fig. 5 Confocal laser scanning microscope examination. a: Control group $\times 5 \mu \mathrm{m}$. b:Control group $\times 1 \mu \mathrm{m}$. c: $2.81 \mu \mathrm{g} / \mathrm{ml} \times 5 \mu \mathrm{m}$. d: $2.81 \mu \mathrm{g} / \mathrm{ml} \times 1 \mu \mathrm{m}$. e: $5.63 \mu \mathrm{g} / \mathrm{ml} \times 5 \mu \mathrm{m}$. f: $5.63 \mu \mathrm{g} / \mathrm{ml} \times 1 \mu \mathrm{m}$. g: $11.3 \mu \mathrm{g} / \mathrm{ml} \times 5 \mu \mathrm{m}$. h: $11.3 \mu \mathrm{g} / \mathrm{ml} \times 1 \mu \mathrm{m}$. i:Positive group $\times 5 \mu \mathrm{m}$. j:Positive group $\times 1 \mu \mathrm{m}$

lower in the presence of ampicillin (Fig. 5-1, Fig. 5-2). The bacteria were scattered with clear boundaries and no mucinous coating, indicating a serious loss of BBF formation.

\section{Discussion}

S. aureus is an important nosocomial pathogen in hospitals, and it commonly forms biofilms [13]. The current treatments are antibiotics; however, long-term use of antibiotics results in increased resistance. We have shown that reducing the number of bacteria does not reduce biofilm formation [14]. This suggests that antibacterial drugs may not be effective in removing bacterial biofilms. The extracellular polysaccharide coating on biofilms helps bacteria within the membrane to evade the immune system of the human body [15-17]. Studies have shown that at least $65 \%$ of human infections are caused by bacteria and biofilm formation [18-21]. Therefore, it is important to investigate effective drugs that remove bacterial biofilms in resistant strains [22].

Natural active ingredients extracted from plants have unique advantages for the treatment of $S$. aureus biofilm infections [14, 23-31]. Flavonoids, such as quercetin, naringenin, and dihydrochalcone, in these extracts have been reported to have antibiofilm effects [23-25, 32]. In addition, kaempferol (flavonoids) can inhibit the biofilm formation of Staphylococcus aureus [33]. The mechanism may be due to the fact that the outer membrane of bacteria has a narrow pore protein that slows down the penetration of hydrophilic antibiotics. All flavonoids are hydrophobic, suggesting an increased potential for biofilm treatment [32].

In the present study, the results of the microplate assays indicate that FZM effectively inhibits the in vitro formation of $S$. aureus biofilms. By increasing the concentration of FZM, the rate of biofilm formation reduced steadily. Biofilm thickness is one of the criteria used to assess the ability of compounds to remove biofilms [34]. In our study, we found that FZM reduced the thickness of the biofilms and destroyed the 3D structure, thereby inhibiting biofilm maturation. At the same time, the viable and dead bacteria in the biofilm were significantly reduced, suggesting that FZM can penetrate the biofilm matrix and act directly on the bacteria.

Current research shows that the removal of adhesion proteins, the increase in bacterial $\mathrm{pH}$, and the destruction of the bacterial quorum sensing system are the key factors for removing S. aureus biofilms [24, 25, 27, 35]. Studies have confirmed that scavenging free radicals and reactive oxygen species from flavonoids can effectively change the bacterial $\mathrm{pH}$ environment, suggesting that this is one of the mechanisms by which flavonoids can remove biofilms. FZM removes reactive oxygen species, has antioxidative and antiinflammatory effects, and improves the intestinal microenvironment [32, 36-44]. In our study, subtle changes in BBFs were observed by SEM. In the negative control, the pores for substance exchange and the 3D structure of the $S$. aureus biofilm were gradually destroyed after FZM treatment. Exopolysaccharides were cleared, and the bacteria were gradually exposed. This further confirmed that FZM can 
significantly improve BBF detachment. It may remove bacterial exopolysaccharides and disrupt the channels available for substance exchange in the biofilm.

\section{Conclusion}

FZM can inhibit biofilm formation, improve the bacterial $\mathrm{pH}$ environment, and eliminate the hydrophobic effect of reactive oxygen species and flavonoids. Further studies are required to investigate the mechanism of action of FZM on the bacterial quorum sensing system.

\section{Abbreviations}

BBFs: Bacterial biofilms; BHI: Brain heart infusion broth; CLSM: Confocal laser scanning microscope; FZM: Flavonoids-rich Ziziphus jujuba Mill. extract; PBS: Phosphate buffered solution; SEM: Scanning electron microscope

\section{Acknowledgements}

We acknowledge the support received from Central Laboratory of Xinjiang Medical University.

\section{Authors' contributions}

WM, AA, TY, and GW participated in the design of the study data analyses and manuscript preparation. LS, JS, and MZ performed experiments. All authors read and approved the final manuscript.

\section{Funding}

This work was supported by the Xinjiang traditional Chinese medicine new drug research and development projects (No.Q2015-01-06) and the National Natural Science Foundation of China (No.81660695) and Xinjiang Tianshan talent projects (No.2-14-01) and the Training project for outstanding young people in science and technology in the Xinjiang (No.qn2015jq005). All the above funds provided financial support for this study. (No.Q2015-0106) is a pharmacodynamic study of each individual medicinal material in a marketed compound traditional Chinese medicine preparation,the medicinal materials used in this manuscript are one of the ingredients of the compound traditional Chinese medicine preparation.(No.81660695) is a pharmacodynamic study of traditional medicines in Xinjiang,the medicinal materials involved in this manuscript are Xinjiang national medicine,the relevant research results of this manuscript support the establishment of the above projects.(No.2-14-01) and (No.qn2015jq005) is about the research and development of ethnic medicine in Xinjiang, based on the above research, this manuscript further explores the antibacterial effect of medicinal materials.

\section{Availability of data and materials}

The datasets used and/or analyzed during the current study are available from the corresponding author on reasonable request.

\section{Ethics approval and consent to participate}

Not applicable.

\section{Consent for publication}

Not applicable.

\section{Competing interests}

The authors declare that they have no competing interests.

\section{Author details}

${ }^{1}$ Clinical Medical Research Institute, The First Affiliated Hospital of Xinjiang Medical University, Urumqi 830011, China. ${ }^{2}$ Pharmacology Department, Sanquan College of Xinxiang Medical University, Xinxiang 453000, China. ${ }^{3}$ Central Laboratory of Xinjiang Medical University, Urumqi 830011, China. ${ }^{4}$ Heart Center, The First Affiliated Hospital of Xinjiang Medical University, Urumgi 830011 , China.
Received: 13 February 2018 Accepted: 27 January 2020

Published online: 17 June 2020

\section{References}

1. Sampson W. Studying herbal remedies. N Engl J Med. 2005:353:337-9.

2. Tahergorabi Z, Abedini MR, Mitra M, Fard MH, Beydokhti H. "Ziziphus jujuba": A red fruit with promising anticancer activities. Pharmacogn Rev. 2015;9:99106.

3. Ji X, Peng Q, Yuan Y, Shen J, Xie X, Wang M. Isolation, structures and bioactivities of the polysaccharides from jujube fruit (Ziziphus jujuba mill.): a review. Food Chem. 2017:227:349.

4. Costerton JW, Stewart PS, Greenberg EP. Bacterial biofilms: a common cause of persistent infections. Science. 1999:284:1318-22.

5. Hall-Stoodley L, Costerton JW, Stoodley P. Bacterial biofilms: from the natural environment to infectious diseases. Nat Rev Microbiol. 2004:2:95

6. Paju S, Saarela M, Chen C, et al. Altered antigenicity is seen in the lipopolysaccharide profile of non-serotypeable Actinobacillus actinomycetemcomitans strains. FEMS Immunol Med Microbiol. 2000;27(2): $171-7$.

7. Hess DJ, Henry-Stanley MJ, Wells CL. Can Vancomycin or ampicillin prevent development of staphylococcus Aureus biofilms? J Surg Res. 2012;172(2):1.

8. Watanabe T. Observation of Pseudomonas aeruginosa biofilm with confocal laser scanning microscope. J Japanese Assoc Infect Dis. 1995;69(1):114-22.

9. Chicurel M. Bacterial biofilms and infections. Slimebusters. Nature. 2000; 408(6810):284-6

10. Jitka, Makovcova, Vladimir, et al. Dynamics of mono- and dual-species biofilm formation and interactions between Staphylococcus aureus and Gramnegative bacteria. Microb Biotechnol. 2017.

11. Beaudoin T, Yau YCW, Stapleton PJ, et al. Staphylococcus aureus interaction with Pseudomonas aeruginosa biofilm enhances tobramycin resistance. NPJ Biofilms Microbiomes. 2017;3(1):25

12. Roy $\mathrm{R}$, Tiwari M, Donelli $\mathrm{G}$, et al. Strategies for combating bacterial biofilms: a focus on anti-biofilm agents and their mechanisms of action [J]. Virulence. 2018;9(1):522-54.

13. Sollid JU, Furberg AS, Hanssen AM, Johannessen M. Staphylococcus aureus: determinants of human carriage. Infect Genet Evol. 2014;21:531-41.

14. Alavarce RA, Saldanha LL, Almeida NL, Porto VC, Dokkedal AL, Lara VS. The beneficial effect of Equisetum giganteum L. against Candida biofilm formation: new approaches to denture stomatitis. Evid Based Complement Alternat Med. 2015;2015(1741-427x).

15. Percival SL, Hill KE, Williams DW, Hooper SJ, Thomas DW, Costerton JW. A review of the scientific evidence for biofilms in wounds. Wound Repair Regen. 2012;20:647.

16. Sauer K, Camper AK, Ehrlich GD, Costerton JW, Davies DG. Pseudomonas aeruginosa displays multiple phenotypes during development as a biofilm. J Bacteriol. 2002:184:1140-54.

17. Roland PS. Chronic suppurative otitis media: a clinical overview. Ear Nose Throat J. 2002:81:8-10

18. Pihl M, Arvidsson A, Skepö M, Nilsson M, Givskov M, Tolkernielsen T, et al. Biofilm formation by Staphylococcus epidermidis on peritoneal dialysis catheters and the effects of extracellular products from Pseudomonas aeruginosa. FEMS Immunol Med Microbiol. 2013:67:192-8.

19. Lewis K. Riddle of biofilm resistance. Antimicrob Agents Chemother. 2001; 45:999-1007.

20. Epstein AK, Hochbaum Al, Kim P, Aizenberg J. Control of bacterial biofilm growth on surfaces by nanostructural mechanics and geometry. Nanotechnology. 2011;22:494007.

21. Arciola CR, Baldassarri L, Montanaro L. Presence of icaA and icaD genes and slime production in a collection of staphylococcal strains from catheterassociated infections. J Clin Microbiol. 2001:39(6):2151-6.

22. Howlin RP, Brayford MJ, Webb JS, Cooper JJ, Aiken SS, Stoodley P. Antibiotic-loaded synthetic calcium sulfate beads for prevention of bacterial colonization and biofilm formation in periprosthetic infections. Antimicrob Agents Chemother. 2015;59:111.

23. Lee JH, Regmi SC, Kim JA, Cho MH, Yun H, Lee CS, et al. Apple flavonoid phloretin inhibits Escherichia coli 0157:H7 biofilm formation and ameliorates colon inflammation in rats. Infect Immun. 2011;79:4819-27.

24. Vikram A, Jesudhasan PR, Jayaprakasha GK, Pillai SD, Jayaraman A, Patil BS. Citrus flavonoid represses Salmonella pathogenicity island 1 and motility in S. Typhimurium LT2. Int J Food Microbiol. 2011;145:28-36. 
25. Liu Z, Pan Y, Li X, Jie J, Zeng M. Chemical composition, antimicrobial and anti-quorum sensing activities of pummelo peel flavonoid extract. Ind Crop Prod. 2017;109:862-8.

26. Spini G, Decorosi F, Cerboneschi M, Tegli S, Mengoni A, Viti C, et al. Effect of the plant flavonoid luteolin on Ensifer meliloti, 3001 phenotypic responses. Plant Soil. 2016;399:1-20.

27. Nguyen PTM, Schultze N, Boger C, Alresley Z, Bolhuis A, Lindequist U. Anticaries and antimicrobial activities of methanolic extract from leaves of Cleistocalyx operculatus L. Asian Pac J Trop Biomed. 2017;7:2017.

28. Al-Shabib NA, Husain FM, Ahmad I, Khan MS, Khan RA, Khan JM. Rutin inhibits mono and multi-species biofilm formation by foodborne drug resistant Escherichia coli and Staphylococcus aureus. Food Control. 2017;3:4.

29. Topuzovic MD, Radojevic ID, Dekic MS, Radulovic NS, Vasic SM, Comic LR, et al. Phytomedical investigation of Najas minor all. In the view of the chemical constituents. EXCLI J. 2015:14:496-503.

30. Parai D, Islam E, Mitra J, Mukherjee SK. Effect of Bacoside a on growth and biofilm formation by Staphylococcus aureus and Pseudomonas aeruginosa. Can J Microbiol. 2017;63:169.

31. Arifa M, Muzzamil W, Iram L, Najma A. Phytochemical, antimicrobial, and toxicological evaluation of traditional herbs used to treat sore throat. Biomed Res Int. 2016;2016:1-9.

32. Nobakht M, Trueman SJ, Wallace HM, Brooks PR, Streeter KJ, Katouli M. Antibacterial properties of flavonoids from Kino of the eucalypt tree, Corymbia torelliana. Plants. 2017;6:1.

33. Sheng C, Jianlin Y, Zejia L, Nianhai H, Fengjuan S. Experimental study on effect of mesnaon pseudomonas aeruginosa biofilm. Chin J Nosocomiol. 2013;23:1749-52

34. Di $M$, Dacheng $W$, Fengjiao $C$, et al. Kaempferol inhibits the primary attachment phase of biofilm formation in Staphylococcus aureus. Front Microbiol. 2017;8:2263-74.

35. Pejin B, Ciric A, Glamoclija J, Nikolic M, Stanimirovic B, Sokovic M. Quercetin potently reduces biofilm formation of the strain Pseudomonas aeruginosa PAO1 in vitro. Curr Pharm Biotechnol. 2015;16:12.

36. Chen J, Liu X, Li Z, Qi A, Yao P, Zhou Z, et al. A review of dietary Ziziphus jujuba fruit (jujube): developing health food supplements for brain protection. Evid Based Complement Alternat Med. 2017;2017:1-10.

37. Cui DN, Wang X, Chen JQ, Lv B, Zhang P, Zhang W, et al. Quantitative evaluation of the compatibility effects of huangqin decoction on the treatment of irinotecan-induced gastrointestinal toxicity using untargeted metabolomics. Front Pharmacol. 2017;8:221.

38. Rodrã-Guez VJ, Rodrã-Guez VL. Experimental and clinical pharmacology of Ziziphus jujuba Mills. Phytother Res. 2017;31:347-65.

39. Kandimalla R, Dash S, Kalita S, Choudhury B, Malampati S, Kalita K, et al. Protective effect of bioactivity guided fractions of Ziziphus jujuba Mill. root bark against hepatic injury and chronic inflammation via inhibiting inflammatory markers and oxidative Stress. Front Pharmacol. 2016;7:1.

40. Han D, Wan C, Liu F, Xu X, Jiang L, Xu J. Jujuboside a protects H9C2 cells from isoproterenol-induced injury via activating PI3K/Akt/mTOR signaling pathway. Evid Based Complement Alternat Med. 2016;2016:9593716.

41. Rajopadhye A, Upadhye AS. Estimation of bioactive compound, maslinic acid by HPTLC, and evaluation of hepatoprotective activity on fruit pulp of Ziziphus jujuba Mill. cultivars in India. Evid Based Complement Alternat Med. 2016;2016:4758734.

42. Chen J, Lam CT, Li Z, Yao P, Lin H, Dong TT, et al. Extract of Ziziphus jujuba fruit (jujube) stimulates expression of enzymes responsible for heme recycle via anti-oxidant response element in cultured murine macrophages. Phytother Res. 2016;30:267.

43. Zhang $H$, Jiang $L$, Ye $S$, Ye $Y$, Ren F. Systematic evaluation of antioxidant capacities of the ethanolic extract of different tissues of jujube (Ziziphus jujuba mill.) from China. Food Chem Toxicol. 2010;48:1461-5.

44. Salimi M, Sarkhail P, Sarkheil P, Mostafapour Kandelous H, Baeeri M. Evaluation of anti-melanogenic activity of Ziziphus jujuba fruits obtained by two different extraction methods. Res J Pharmacognosy (RJP). 2016;3:1-7.

\section{Publisher's Note}

Springer Nature remains neutral with regard to jurisdictional claims in published maps and institutional affiliations.

Ready to submit your research? Choose BMC and benefit from:

- fast, convenient online submission

- thorough peer review by experienced researchers in your field

- rapid publication on acceptance

- support for research data, including large and complex data types

- gold Open Access which fosters wider collaboration and increased citations

- maximum visibility for your research: over $100 \mathrm{M}$ website views per year

At BMC, research is always in progress.

Learn more biomedcentral.com/submissions 